\title{
Similarity Analysis between Scale Model and Prototype of Large Vibrating Screen
}

\author{
Zerong Zhang, Yongyan Wang, and Zhimin Fan \\ College of Electromechanical Engineering, Qingdao University of Science and Technology, Qingdao 266061, China \\ Correspondence should be addressed to Zerong Zhang; cba1998@126.com
}

Received 6 February 2015; Revised 31 May 2015; Accepted 1 June 2015

Academic Editor: Tai Thai

Copyright (c) 2015 Zerong Zhang et al. This is an open access article distributed under the Creative Commons Attribution License, which permits unrestricted use, distribution, and reproduction in any medium, provided the original work is properly cited.

\begin{abstract}
In order to predict the physical characteristics of the large vibrating screen from its scale-down model, the similarity ratios of the frequency response functions, mode shapes, and dynamic stresses between the prototype and the scale model screen are built according to the similarity theory. The natural frequencies and modal shapes are extracted from the frequency response function by means of modal tests, in which the relative error of the natural frequencies is less than $9 \%$ and the modal shapes are consistent between the prototype and the model. The operating condition parameters including dynamic stress, displacement, velocity, and acceleration were also measured and conform to the similarity criteria. The results show that the inherent and operating condition parameters of the large vibrating screen can be obtained from the scale-down model conveniently, which provides an effective method for structural optimization and substructure coupling analysis of the large vibrating screen.
\end{abstract}

\section{Introduction}

Large vibrating screens are widely used for sieving and dewatering in mining, metallurgy, and chemical industry. The screen acceleration, frequency, and amplitude affect the separation efficiency and the fatigue life of the vibrating screen; thus, an optimization design should be done for the vibrating screen [1]. For novel large vibrating screen, making prototype will increase the research costs and the test cannot be performed easily and effectively because of the severe operating conditions [2]. Therefore, according to the principle of similarity using scale-down model is an essential method for structural dynamic analysis and optimal design [3]. Rezaeepazhand and Simitses [4] have established a scale model for predicting the free vibration and buckling of laminated shell. Wu et al. [5] have presented the scaling laws for the prediction of the vibration characteristics of a full size crane structure from those of a scale model by means of the similitude theory. Lin et al. [6] have analyzed the influence of pile modulus similarity ratio and geometry similarity ratio on the piles similarity of deflection behavior between model and prototype piles. De Rosa et al. [7] proposed a similitude for the analysis of the dynamic response of acoustoelastic assemblies. The objective of this paper is to predict the physical characteristics of a full size large linear vibrating screen by means of a scale-down model screen.

\section{The Similarity Analysis of Modal Parameters between Scale Model and the Prototype}

2.1. The Similarity Derivation of Modal Parameters of the Large Vibrating Screen. According to the similarity theory $[8,9]$, the prototype and scale model need to meet the following similarity criteria: geometry similarity, stress-strain similarity, mass and the gravity similarity, and the initial conditions and boundary conditions similarity. When only studying the inherent characteristics of the vibrating screen structure, the inertial force and the elastic restoring force need to obey the similitude rules. The gravity has less effect on the natural vibration characteristics; thus, its similar requirements could be ignored [10-12].

The free vibration equation of the prototype of the large vibrating screen is

$$
\mathbf{m}_{p} \ddot{\mathbf{x}}_{p}+\mathbf{k}_{p} \mathbf{x}_{p}=0 .
$$


The subscripts $p$ and $m$ represent the prototype and the scale model, respectively, and if we define $C_{m}, C_{\rho}, C_{l}$, $C_{x}, C_{t}$, and $C_{E}$ as similarity ratio of mass, density, length, displacement, time, and modulus of elasticity between the vibrating screen prototype and model, respectively, then (1) can be rewritten as

$$
C_{m} \mathbf{m}_{m} \frac{d^{2}\left(C_{x} \mathbf{x}_{m}\right)}{d\left(C_{t} t_{m}\right)^{2}}+C_{k} \mathbf{k}_{m} C_{x} \mathbf{x}_{m}=0 .
$$

Then, the similarity ratio of the natural frequency can be derived:

$$
C_{f}=\frac{f_{p}}{f_{m}}=\frac{l_{m}}{l_{p}}\left(\frac{\rho_{m}}{\rho_{p}}\right)^{1 / 2}\left(\frac{E_{m}}{E_{p}}\right)^{-1 / 2}
$$

The similarity ratio of the frequency response function can be deduced as follows:

$$
\frac{\left(H_{i j}\right)_{p}}{\left(H_{i j}\right)_{m}}=\frac{\left(X_{i} / F_{j}\right)_{p}}{\left(X_{i} / F_{j}\right)_{m}}=\frac{C_{x}}{C_{F}}=\frac{1}{C_{l} C_{E}} .
$$

The similarity ratio of the mode shape is

$$
\frac{\left(\psi_{i r}\right)_{p}}{\left(\psi_{i r}\right)_{m}} \propto \frac{\left({ }_{r} H_{i j}\right)_{p}}{\left({ }_{r} H_{i j}\right)_{m}}=\frac{1}{C_{l} C_{E}}
$$

The scale factor of the mode shape is a constant ratio when the material and size of the vibrating screen have been confirmed. Since the mode shape is the amplitude ratio of each point, if each of the mode shapes of the prototype and model is standardized at the same location, then

$$
\left\{\psi_{r}\right\}_{p}=\left\{\psi_{r}\right\}_{m} .
$$

According to the expression of the frequency response function,

$$
H_{i j}=\sum_{r=1}^{N} H_{i j}=\sum_{r=1}^{N} \frac{\varphi_{i r} \varphi_{j r}}{k_{r}-\omega^{2} m_{r}+j \omega c_{r}} .
$$

When $\omega \gg \omega_{r}$,

$$
{ }_{r} H_{i j}=\frac{\varphi_{i r} \varphi_{j r}}{-\omega^{2} m_{r}}
$$

Then, we obtained

$$
\left(\frac{\varphi_{i r} \varphi_{j r}}{-\omega^{2} m_{r}}\right)_{p}:\left(\frac{\varphi_{i r} \varphi_{j r}}{-\omega^{2} m_{r}}\right)_{m}=\left({ }_{r} H_{i j}\right)_{p}:\left({ }_{r} H_{i j}\right)_{m} .
$$

Thus, the similarity ratio of the modal mass can be derived:

$$
\frac{\left(m_{r}\right)_{p}}{\left(m_{r}\right)_{m}}=\frac{\omega_{m}^{2}\left({ }_{r} H_{i j}\right)_{m}}{\omega_{p}^{2}\left({ }_{r} H_{i j}\right)_{p}}=\left(C_{l}\right)^{3} C_{\rho} .
$$

The similarity ratio of the modal stiffness can be deduced as follows:

$$
\frac{\left(k_{r}\right)_{p}}{\left(k_{r}\right)_{m}}=\frac{\left(\omega_{r}^{2} m_{r}\right)_{p}}{\left(\omega_{r}^{2} m_{r}\right)_{m}}=C_{l} C_{E}
$$

According to the viscous damping theory,

$$
F=c v=c \frac{d x}{d t}
$$

With the similarity theory, (12) can be rewritten as

$$
C_{F} F_{m}=C_{c} c_{m} \frac{d\left(C_{x} x_{m}\right)}{d\left(C_{t} t_{m}\right)} .
$$

Then, the similarity ratio of the modal damping can be derived:

$$
C_{c}=\frac{C_{F} C_{t}}{C_{x}}=C_{l}^{2}\left(C_{\rho} C_{E}\right)^{1 / 2} .
$$

According to the similarity ratios of the modal parameters derived from the above, the similar relations of the modal parameters of the large vibrating screen were calculated and listed in Table 1 when the 1:5 similar test model and the prototype both are manufactured using the same material of mild carbon steel.

2.2. The Similarity Experiment of Modal Parameters of the Large Vibrating Screen. The prototype of the $27 \mathrm{~m}^{2}$ large linear vibrating screen with width of $3.6 \mathrm{~m}$ and length of $7.5 \mathrm{~m}$ is shown in Figure 1(a). The single-point excitation and multipoint response method was used to test the modal parameters and the HP5423A structure dynamic analyzer was used to get frequency response function from test data [13]. The scaledown test model screen is shown in Figure 1(b), which used multipoint excitation and single-point response method to test. The structure was excited by impact hammer and the output signal was measured by accelerometer $[14,15]$.

In order to analyze the similarity of frequency response function between the prototype and model screen, the imaginary parts of the frequency response function curve are shown in Figure 2, the frequency of prototype ranging from 0 to $60 \mathrm{~Hz}$ and the frequency of model ranging from 0 to $300 \mathrm{~Hz}$ accordingly. The frequency response function curves and the natural frequencies of the model are consistent with the prototype according to the similarity ratio of $1 / 5$. Equation (10) shows that the modal mass is inversely proportional to the frequency response function value and the square of the circular frequency, which has been verified by the frequency response function curve shown in Figure 2. For instance, when the natural frequency is $50 \mathrm{~Hz}$ of the prototype corresponding to $250 \mathrm{~Hz}$ of the model, the value of the imaginary part of the frequency response function is $-0.016 \mathrm{~m} \cdot \mathrm{s}^{-2} \cdot \mathrm{N}^{-1}$ of the prototype corresponding to $-0.08 \mathrm{~m} \cdot \mathrm{s}^{-2} \cdot \mathrm{N}^{-1}$ of the model, which is consistent with the similarity ratio.

According to the natural frequencies extracted from the frequency response function, the mode shapes can be seen 
TABLE 1: The similarity ratios of the modal parameters of the large vibrating screen.

\begin{tabular}{lcccc}
\hline $\begin{array}{l}\text { Ratio of natural frequency } \\
f_{p} / f_{m}\end{array}$ & $\begin{array}{c}\text { Ratio of modal shape } \\
\left\{\Psi_{r}\right\}_{p} /\left\{\Psi_{r}\right\}_{m}\end{array}$ & $\begin{array}{c}\text { Ratio of modal mass } \\
\left(m_{r}\right)_{p} /\left(m_{r}\right)_{m}\end{array}$ & $\begin{array}{c}\text { Ratio of modal stiffness } \\
\left(k_{r}\right)_{p} /\left(k_{r}\right)_{m}\end{array}$ & $\begin{array}{c}\text { Ratio of modal damping } \\
\left(c_{r}\right)_{p} /\left(c_{r}\right)_{m}\end{array}$ \\
\hline 0.2 & 1 & 125 & 5 & 25 \\
\hline
\end{tabular}

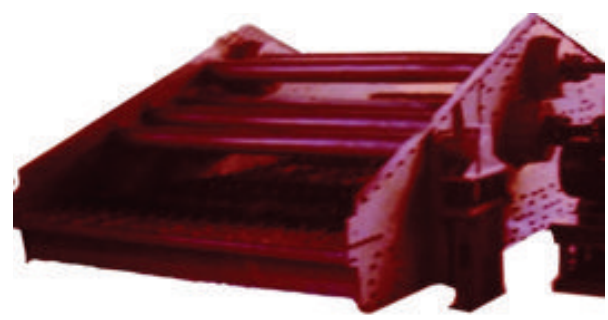

(a)

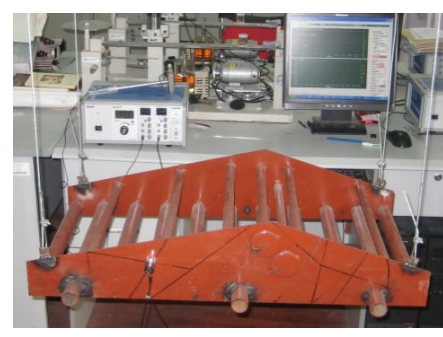

(b)

Figure 1: The prototype and model of the vibrating screen. (a) The prototype of $27 \mathrm{~m}^{2}$ linear vibrating screen. (b) The 1:5 scale model screen.

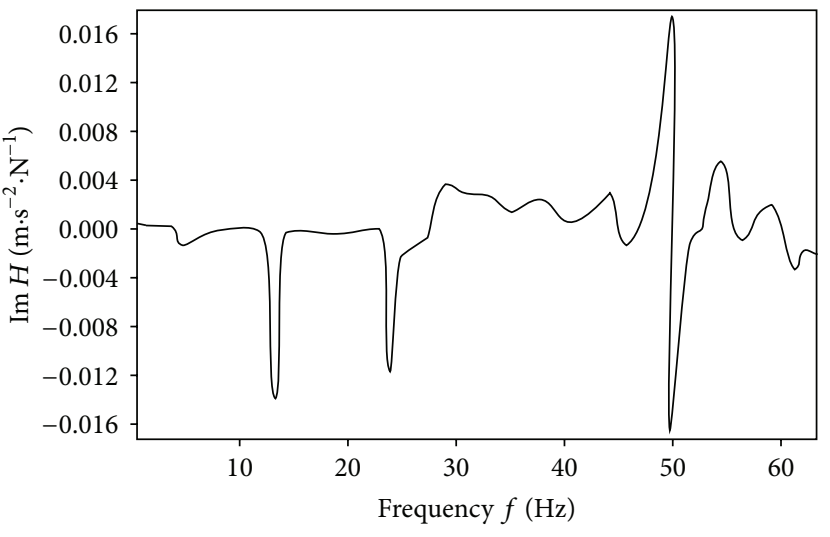

(a)

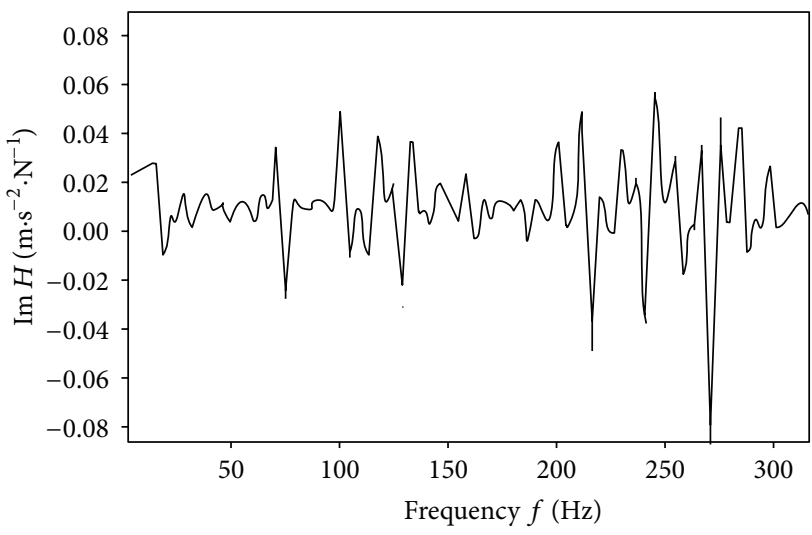

(b)

Figure 2: The imaginary part of the frequency response function curve. (a) The frequency response function of the prototype. (b) The frequency response function of the model.

clearly in the form of animation by signal processing software, in which the sixth-order mode shapes of the prototype and model screen are shown in Figure 3. In the first ten order modes, the side panel bending deformation is more obviously revealed by the mode shapes. The main reason is that the side panel thickness of the $27 \mathrm{~m}^{2}$ vibrating screen is relatively thin, owing to shell structure; thus, the overall stiffness is low and easy for deformation. In order to improve its dynamic characteristics and prolong its fatigue life, the stiffness of the side panel can be increased by adding the number of beams or reasonable decorated stiffener on the side panel. At the same time, the deformation of the beam is larger, indicting the stiffness of the beams is not adapted to the working characteristic of the vibrating screen, which can use rectangular hollow beam to make it conform to the requirement of the vibrating screen.

The first seven order natural frequencies, modal masses, and modal stiffness of the $27 \mathrm{~m}^{2}$ linear vibrating screen prototype and the model are listed in Table 2. Through comparing the scale-down model and the prototype screen, the maximum relative error is $8.7 \%$ of the natural frequencies, the maximum relative error is $8.9 \%$ of the modal masses, and the maximum relative error is $9.7 \%$ of the stiffness. The reasons for errors are mainly that the scale-down model has a certain degree of simplification compared to the prototype and measurement errors. But according to the similarity theory, the test results of the model and prototype screen are consistent within the engineering permissible errors.

\section{The Similarity Analysis of Operating Condition Parameters between the Scale Model and the Prototype}

3.1. The Similarity Derivation of Operating Condition Parameters of the Large Vibrating Screen. In operating condition, the large vibrating screen is excited by harmonic force and its differential equation of motion is [16]

$$
\mathbf{m} \ddot{\mathbf{x}}+\mathbf{c} \dot{\mathbf{x}}+\mathbf{k} \mathbf{x}=\mathbf{F}(t) .
$$




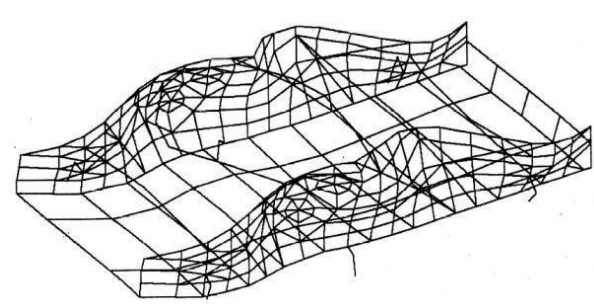

(a)

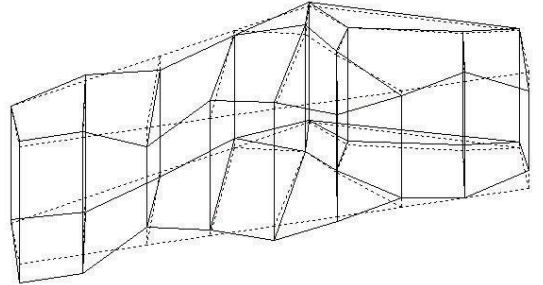

(b)

Figure 3: The sixth mode shape of the prototype compared to the model screen. (a) The bending mode shape of the prototype. (b) The bending mode shape of the model.

TABLE 2: The similar relations of the natural frequency, modal mass, and modal stiffness.

\begin{tabular}{|c|c|c|c|c|c|c|}
\hline Mode number & $\begin{array}{c}\text { Natural frequency } \\
\text { of the prototype } \\
f_{p} / \mathrm{Hz}\end{array}$ & $\begin{array}{c}\text { Natural frequency } \\
\text { of the model } \\
f_{m} / \mathrm{Hz}\end{array}$ & $\begin{array}{l}\text { Modal mass of the } \\
\text { prototype } \\
\left(m_{r}\right)_{p}(\mathrm{Kg})\end{array}$ & $\begin{array}{c}\text { Modal mass of the } \\
\text { model } \\
\left(m_{r}\right)_{m}(\mathrm{Kg})\end{array}$ & $\begin{array}{c}\text { Modal stiffness of } \\
\text { the prototype } \\
\left(k_{r}\right)_{p}(\mathrm{~N} / \mathrm{m})\end{array}$ & $\begin{array}{c}\text { Modal stiffness of } \\
\text { the model } \\
\left(k_{r}\right)_{m}(\mathrm{~N} / \mathrm{m})\end{array}$ \\
\hline 1 & 1.16 & 5.97 & $2.01 E+4$ & $1.69 E+2$ & $1.2 E+8$ & $2.5 E+7$ \\
\hline 2 & 4.36 & 23.71 & $2.18 E+4$ & $1.83 E+2$ & $1.74 E+9$ & $3.68 E+8$ \\
\hline 3 & 6.98 & 30.17 & $1.31 E+4$ & $1.12 E+2$ & $4.26 E+9$ & $9.35 E+8$ \\
\hline 4 & 12.47 & 60.18 & $5.78 E+5$ & $4.68 E+3$ & $3.43 E+10$ & $7.23 E+9$ \\
\hline 5 & 23.41 & 112.84 & $8.61 E+5$ & $6.94 E+3$ & $4.24 E+10$ & $8.96 E+9$ \\
\hline 6 & 26.95 & 130.84 & $9.52 E+5$ & $7.02 E+3$ & $1.46 E+9$ & $2.83 E+8$ \\
\hline 7 & 29.96 & 152.07 & $9.91 E+5$ & $8.63 E+3$ & $3.79 E+9$ & $7.92 E+8$ \\
\hline
\end{tabular}

TABLE 3: The similar relations of the operating condition parameters of large vibrating screen.

\begin{tabular}{|c|c|c|c|c|c|c|c|}
\hline $\begin{array}{l}\text { Ratio of time } \\
C_{t}\end{array}$ & $\begin{array}{c}\text { Ratio of excited } \\
\text { force } \\
C_{F} \\
\end{array}$ & $\begin{array}{c}\text { Ratio of } \\
\text { dynamic stress } \\
C_{\sigma} \\
\end{array}$ & $\begin{array}{c}\text { Ratio of } \\
\text { displacement } \\
C_{x} \\
\end{array}$ & $\begin{array}{c}\text { Ratio of velocity } \\
C_{v}\end{array}$ & $\begin{array}{c}\text { Ratio of } \\
\text { acceleration } \\
C_{a} \\
\end{array}$ & $\begin{array}{l}\text { Ratio of stiffness } \\
\qquad C_{k}\end{array}$ & $\begin{array}{c}\text { Ratio of } \\
\text { dynamic strain } \\
C_{\varepsilon}\end{array}$ \\
\hline 5 & 25 & 1 & 5 & 1 & 0.2 & 5 & 1 \\
\hline
\end{tabular}

The similarity ratios are substituted into (15) to obtain

$$
\begin{aligned}
C_{m} & \mathbf{m}_{m} \frac{d^{2}\left(C_{x} \mathbf{x}_{m}\right)}{d\left(C_{t} t_{m}\right)^{2}}+C_{c} \mathbf{c} \frac{d\left(C_{x} \mathbf{x}_{m}\right)}{d\left(C_{t} t_{m}\right)}+C_{k} \mathbf{k}_{m} C_{x} \mathbf{x}_{m} \\
& =C_{F} \mathbf{F}_{m}(t) .
\end{aligned}
$$

According to the similarity theory, (16) can be deduced:

$$
\frac{C_{\rho} C_{l}^{3} C_{x}}{C_{t}^{2}}=\frac{C_{c} C_{x}}{C_{t}}=C_{E} C_{l} C_{x}=C_{F}
$$

Equating the exponents of the two sides of (17) gives the following relationships:

$$
\begin{aligned}
& C_{t}=C_{l} \sqrt{\frac{C_{\rho}}{C_{E}}}, \\
& C_{c}=C_{E} C_{t} C_{l}, \\
& C_{F}=C_{E} C_{x} C_{l} .
\end{aligned}
$$

In addition, other similarity ratios can be derived [17]:

$$
\begin{aligned}
& C_{\sigma}=C_{E}, \\
& C_{x}=C_{l}, \\
& C_{v}=\sqrt{\frac{C_{E}}{C_{\rho}}}, \\
& C_{a}=\frac{C_{E}}{C_{\rho} C_{l}}, \\
& C_{k}=C_{E} C_{l}, \\
& C_{\varepsilon}=1 .
\end{aligned}
$$

According to the similarity ratios of the operating condition parameters derived from the above, the similar relations of the operating condition parameters of the large vibrating screen were calculated and listed in Table 3 when the 1:5 similar test model and the prototype both are manufactured using the same material of mild carbon steel.

3.2. The Similarity Experiment of Operating Condition Parameters of the Large Vibrating Screen. According to the similar 


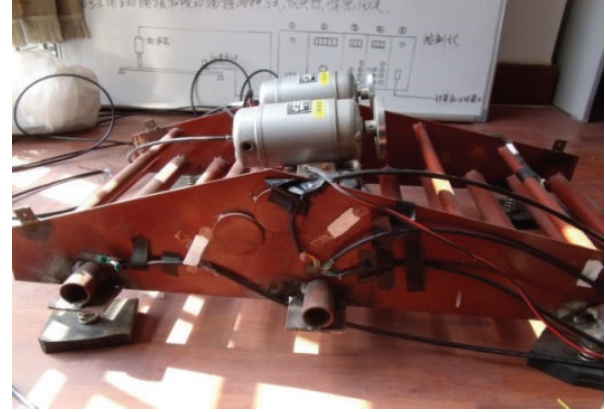

Figure 4: The strain test photo for the model screen.

relations of the operating condition parameters of the large vibrating screen shown in Table 3, the excited force for the scale model is $1 / 25$ of the prototype, namely, $9.6 \mathrm{kN}$; the support stiffness of the spring is $1 / 5$ of the prototype screen, which is $120 \mathrm{~N} / \mathrm{m}$. The damping performance of model similar to the prototype is very difficult, which does not produce great influence on the similarity analysis [18-20].

First, the similarity of the dynamic strain in operating condition was tested, using resistance strain gauge, $45^{\circ}$ strain rosettes, and multichannel experimental apparatus to measure dynamic strain of the beam and side panel. The experimental picture of the dynamic strain test of the model screen is shown in Figure 4. The time history of strain for the midpoint of the 5 \# floor beam is shown in Figure 5; Figure 5(a) is for the prototype and Figure 5(b) is for the scale-down model. The maximum of the strains of the prototype screen and the scale model are $21.5 \mu \varepsilon$ and $19 \mu \varepsilon$, respectively. The maximum relative error of the dynamic strain is $11.6 \%$. The reasons for error are mainly some details of configuration of the model screen simplified and the size effect, but the time history of strain basically conforms to the similarity criterion between the prototype and the scale model of the vibrating screen.

The displacement similarity of prototype screen compared with model screen is shown in Figure 6 and Figure 6(a) is the prototype screen displacement curve; Figure 6(b) is the scale-down model screen displacement curve. The amplitude of the prototype screen is $4.19 \mathrm{~mm}$ and the amplitude of the model screen is $0.9 \mathrm{~mm}$; the relative error is $7.4 \%$ according to the similarity criterion. The reason for error is that the real operating condition for the prototype is severe and unsteady but the displacement of the model is measured under laboratory conditions.

The velocity similarity of prototype screen compared with model screen is shown in Figure 7 and Figure 7(a) is the prototype screen velocity curve; Figure 7 (b) is the scale-down model screen velocity curve. The maximum velocity of the prototype screen is $407.97 \mathrm{~mm} / \mathrm{s}$, the maximum velocity of the model screen is $428.53 \mathrm{~mm} / \mathrm{s}$, and the relative error is $5.0 \%$ according to the similarity criterion. The level of the velocity similarity is high between the prototype and the scale model of the vibrating screen. The velocity of the prototype screen can be predicted precisely by the scale model according to the associated scaling laws.

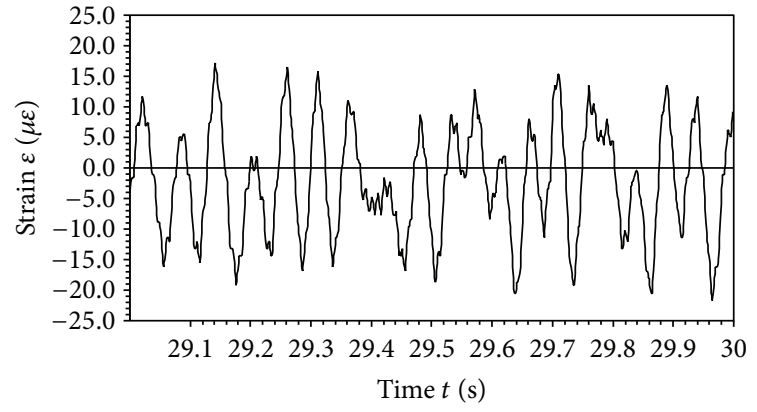

(a)

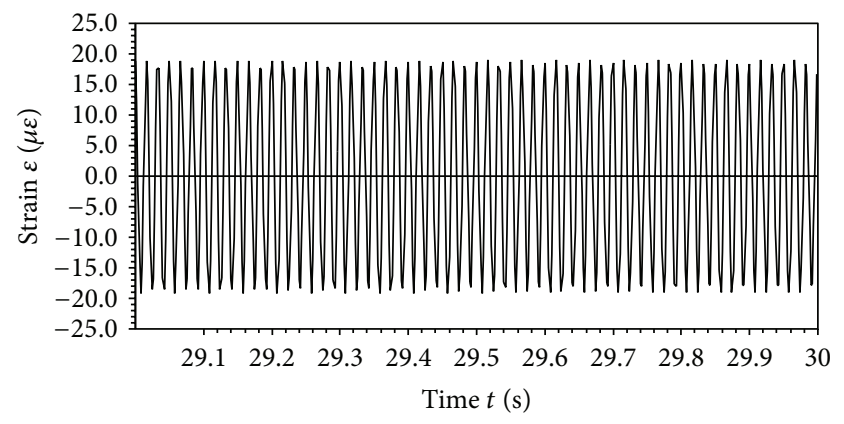

(b)

FIgURE 5: The time history of strain for the midpoint of the 5 \# floor beam. (a) The time history of strain for the midpoint of the 5 \# floor beam of the prototype. (b) The time history of strain for the midpoint of the 5 \# floor beam of the scale model.

The acceleration similarity of prototype screen compared with model screen is shown in Figure 8 and Figure 8(a) is the prototype screen acceleration curve; Figure $8(\mathrm{~b})$ is the scale-down model screen acceleration curve. The maximum acceleration of the prototype screen is $41.6 \mathrm{~m} / \mathrm{s}^{2}$, the maximum acceleration of the model screen is $218.76 \mathrm{~m} / \mathrm{s}^{2}$, and the relative error is $5.2 \%$ according to the similarity criterion. It is apparent that the time histories of accelerations between the prototype and the model are also in good agreement according to the similarity ratio. The acceleration of prototype screen can also be accurately predicted by means of the scaledown model.

\section{Conclusions}

According to the similarity theory, the equation analysis method was used to analyze the similarity criterions of the modal parameters for the scale-down model and the prototype of the vibrating screen. The modal parameters of the scale-down model and the prototype were tested by the impact hammer method; the experimental results show that the frequency response functions, natural frequencies, and mode shapes conform to the similarity criteria. Experiments prove that a reasonable scale-down model vibrating screen can replace the prototype vibrating screen for modal testing analysis, which can provide a shortcut to structural modification and substructure coupling analysis of the prototype of the large vibrating screen. 


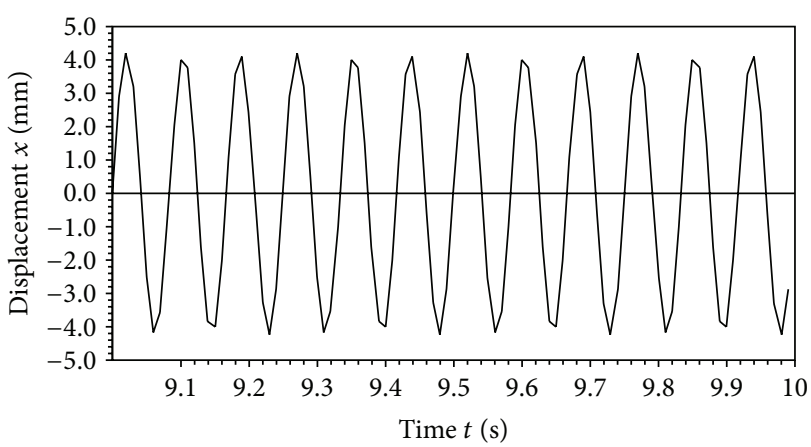

(a)

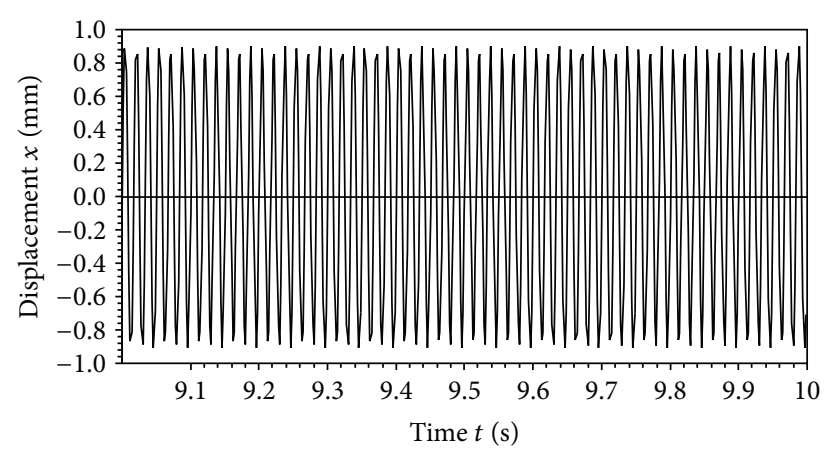

(b)

Figure 6: The displacement similarity of the vibrating screen. (a) The displacement of the prototype screen. (b) The displacement of the model screen.

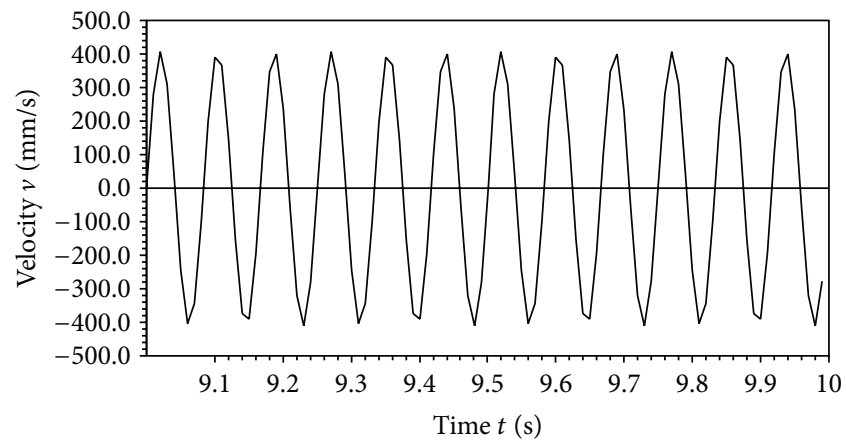

(a)

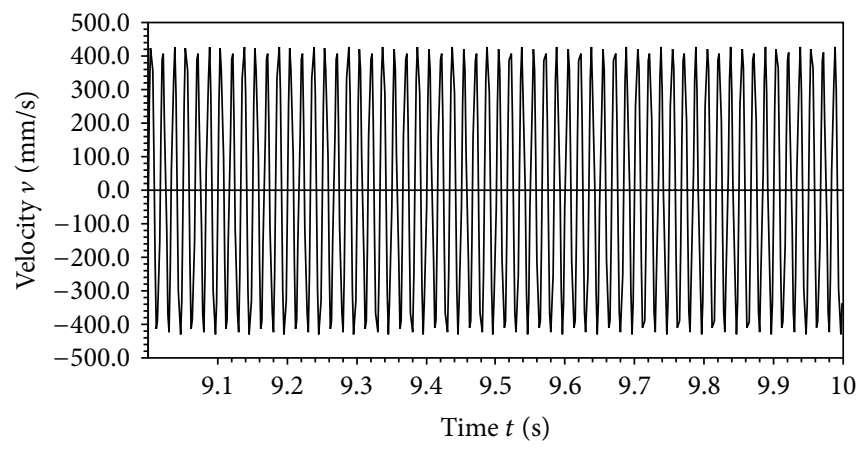

(b)

Figure 7: The velocity similarity of the vibrating screen. (a) The velocity of the prototype screen. (b) The velocity of the model screen.

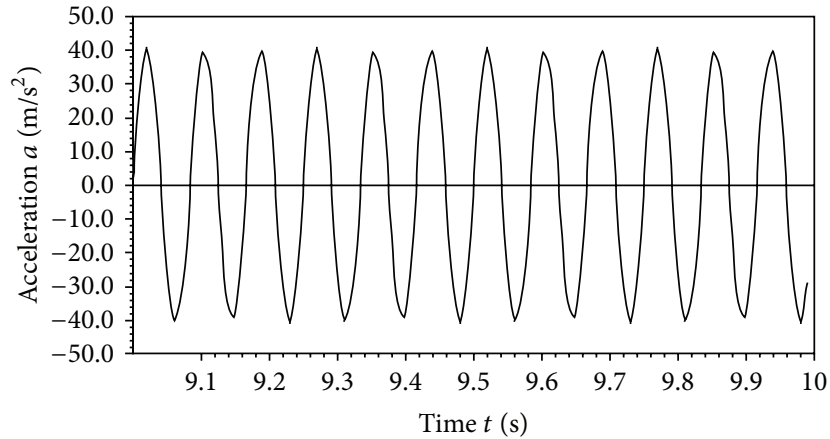

(a)

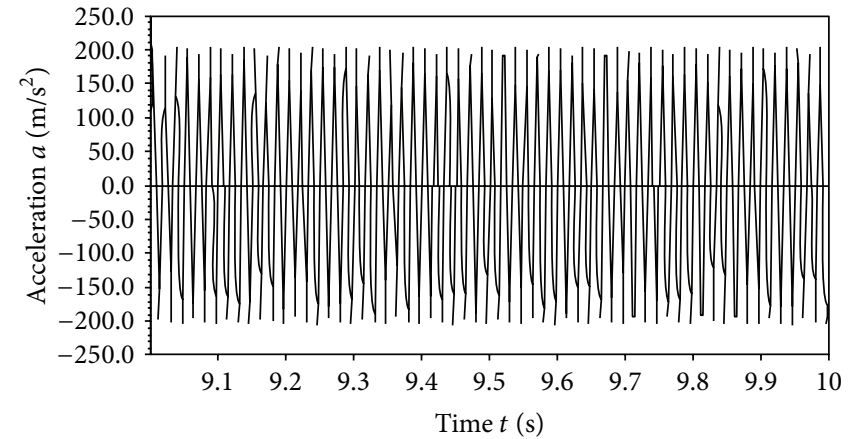

(b)

FIGURE 8: The acceleration similarity of the vibrating screen. (a) The acceleration of the prototype screen. (b) The acceleration of the model screen.

The similarity criterions of the operating condition parameters between scale-down model and the prototype were deduced with equation analysis method. The operating condition parameters including the dynamic strains, displacements, velocities, and accelerations were tested. The operating condition parameters of the scale-down model are consistent with the prototype according to the similarity criterions. Therefore, testing scale-down model can replace the prototype of the large vibrating screen for theoretical and experimental modal analysis.

\section{Conflict of Interests}

The authors declare that there is no conflict of interests regarding the publication of this paper. 


\section{Acknowledgments}

This project is supported by the National Hi-Tech Research and Development Program of China (Grant no. 2006AA04Z408-2) and Shandong Provincial Natural Science Foundation of China (Grant no. ZR2014EEM003).

\section{References}

[1] K. J. Dong, A. B. Yu, and I. Brake, "DEM simulation of particle flow on a multi-deck banana screen," Minerals Engineering, vol. 22, no. 11, pp. 910-920, 2009.

[2] P. W. Cleary, "Large scale industrial DEM modelling," Engineering Computations, vol. 21, no. 2-4, pp. 169-204, 2004.

[3] S. Torkamani, H. M. Navazi, A. A. Jafari, and M. Bagheri, "Structural similitude in free vibration of orthogonally stiffened cylindrical shells," Thin-Walled Structures, vol. 47, no. 11, pp. 1316-1330, 2009.

[4] J. Rezaeepazhand and G. J. Simitses, "Use of scaled-down models for predicting vibration response of laminated plates," Composite Structures, vol. 30, no. 4, pp. 419-426, 1995.

[5] J.-J. Wu, M. P. Cartmell, and A. R. Whittaker, "Prediction of the vibration characteristics of a full-size structure from those of a scale model," Computers \& Structures, vol. 80, no. 18-19, pp. 1461-1472, 2002.

[6] H. Lin, G.-H. Lei, L. Xu, and G.-G. Lei, "Similarity analysis of deflection behavior of laterally loaded piles in 1 g model tests," Journal of Central South University (Science and Technology), vol. 43, no. 9, pp. 3639-3645, 2012 (Chinese).

[7] S. De Rosa, F. Franco, X. Li, and T. Polito, "A similitude for structural acoustic enclosures," Mechanical Systems and Signal Processing, vol. 30, pp. 330-342, 2012.

[8] Z. P. Cai, H. Y. Zhao, S. Wu, and A. Lu, "Prediction of welding deformations by similitude theory," Chinese Journal of Mechanical Engineering, vol. 38, no. 5, pp. 141-144, 2002 (Chinese).

[9] S. D. Ji, L. G. Zhang, X. S. Liu, H. Fang, and D. Yu, "Solution for difficulties in simulation analysis of turbine runner based on similarity theory," Journal of Mechanical Engineering, vol. 46, no. 8, pp. 83-87, 2010 (Chinese).

[10] S. C. Chi and S. S. Lin, "Validation of similitude laws for dynamic structural model test," World Earthquake Engineering, vol. 20, no. 4, pp. 11-20, 2004 (Chinese).

[11] X.-L. Zhang, C.-Y. Zhao, and B.-C. Wen, "Theoretical and experimental study on synchronization of the two homodromy exciters in a non-resonant vibrating system," Shock and Vibration, vol. 20, no. 2, pp. 327-340, 2013.

[12] Y. Y. Wang and Z. R. Zhang, "Similar experimental study of test model and prototype of vibrating screen," Journal of Mechanical Engineering, vol. 47, no. 5, pp. 101-105, 2011 (Chinese).

[13] Y. Y. Wang, Y. L. Tai, and Q. H. Sun, "Study on the dynamic simulation of the large linear vibration mesh," Chinese Journal of Computational Mechanics, vol. 18, no. 1, pp. 94-98, 2001 (Chinese).

[14] M. Ramu, V. Prabhu Raja, and P. R. Thyla, "Establishment of structural similitude for elastic models and validation of scaling laws," KSCE Journal of Civil Engineering, vol. 17, no. 1, pp. 139144, 2013.

[15] Q. Wu, Y. Zhang, and S. Song, "Dynamic characteristics analysis and vibration experiment of upper-time of flight counter (UToFC)," Chinese Journal of Mechanical Engineering, vol. 25, no. 5, pp. 868-874, 2012.
[16] J.-J. Wu, “The complete-similitude scale models for predicting the vibration characteristics of the elastically restrained flat plates subjected to dynamic loads," Journal of Sound and Vibration, vol. 268, no. 5, pp. 1041-1053, 2003.

[17] Z. R. Zhang, Dynamic \& Fatigue Analysis of Large Linear Vibrating Screen and Similar Experimental Studies of Test Model, Qingdao University of Science and Technology, Qing dao, China, 2011, (Chinese).

[18] S. Baragetti and F. Villa, "A dynamic optimization theoretical method for heavy loaded vibrating screens," Nonlinear Dynamics, vol. 78, no. 1, pp. 609-627, 2014.

[19] Q. F. Yang, Y. S. Wang, and Z. H. Zhang, "Scale effects on propeller cavitating hydrodynamic and hydroacoustic performances with non-uniform inflow," Chinese Journal of Mechanical Engineering, vol. 26, no. 2, pp. 414-426, 2013.

[20] Z. Luo, K. Zhang, Q. K. Han, and D. Wang, "Similarity design method of test model of thin-walled short cylindrical shell with complex annular labyrinth," Journal of Mechanical Engineering, vol. 49, no. 21, pp. 132-139, 2013 (Chinese). 

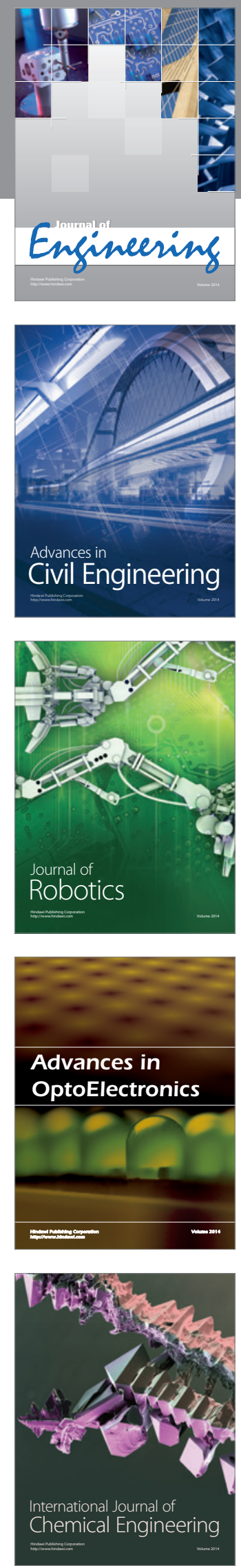

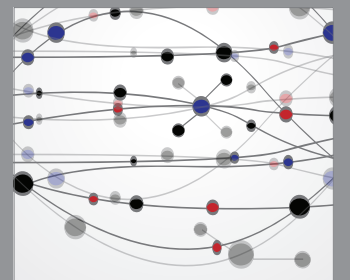

The Scientific World Journal
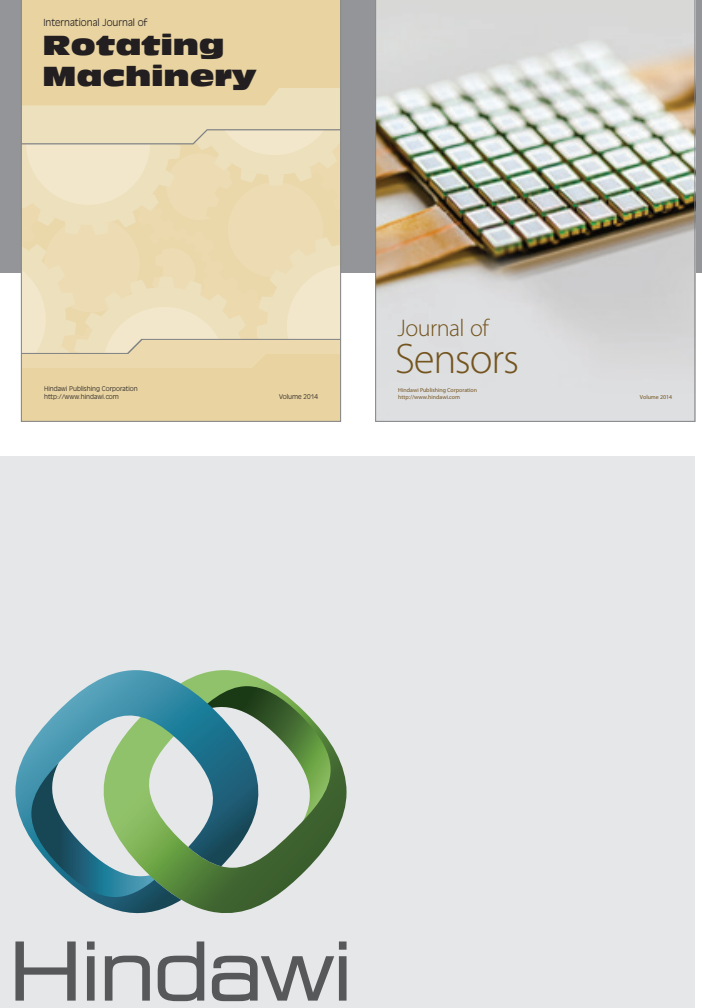

Submit your manuscripts at http://www.hindawi.com
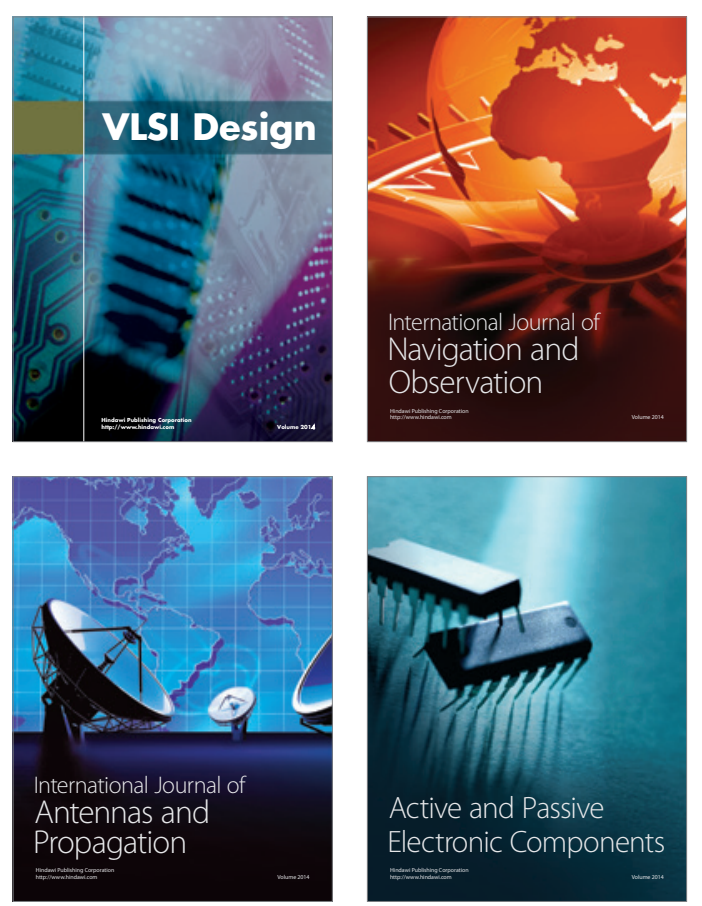
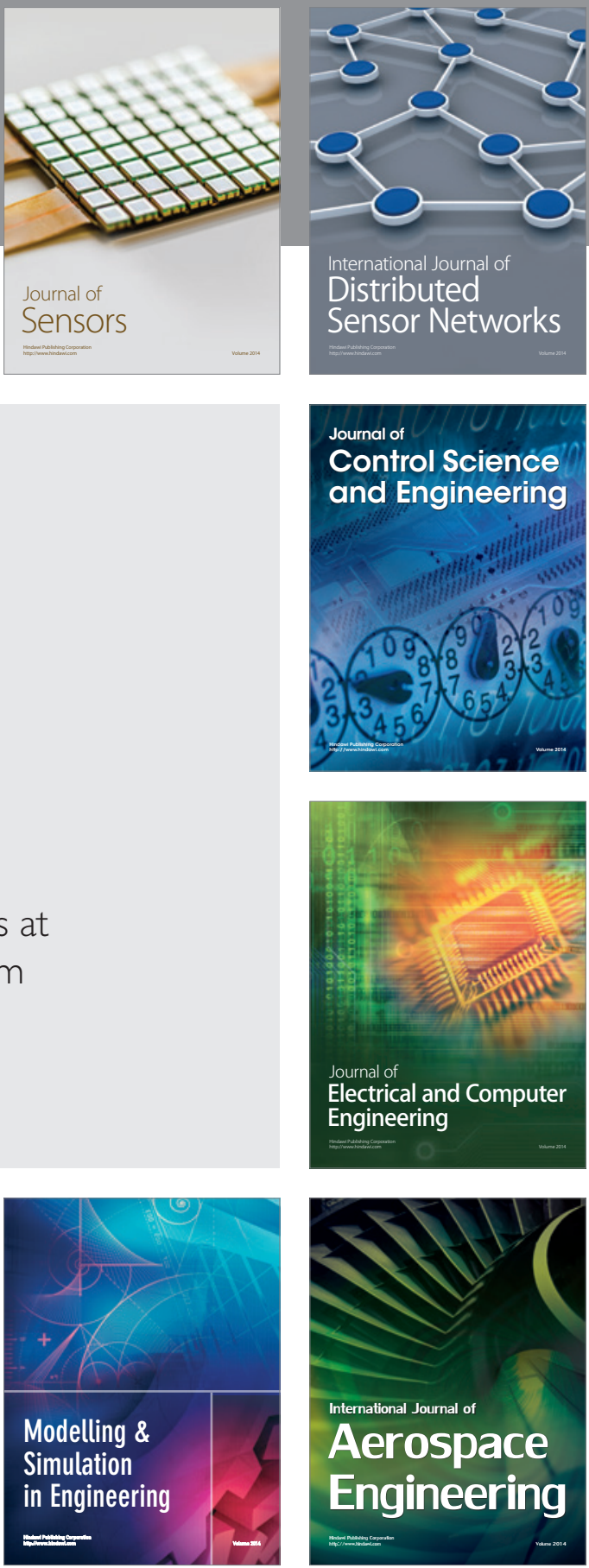

Journal of

Control Science

and Engineering
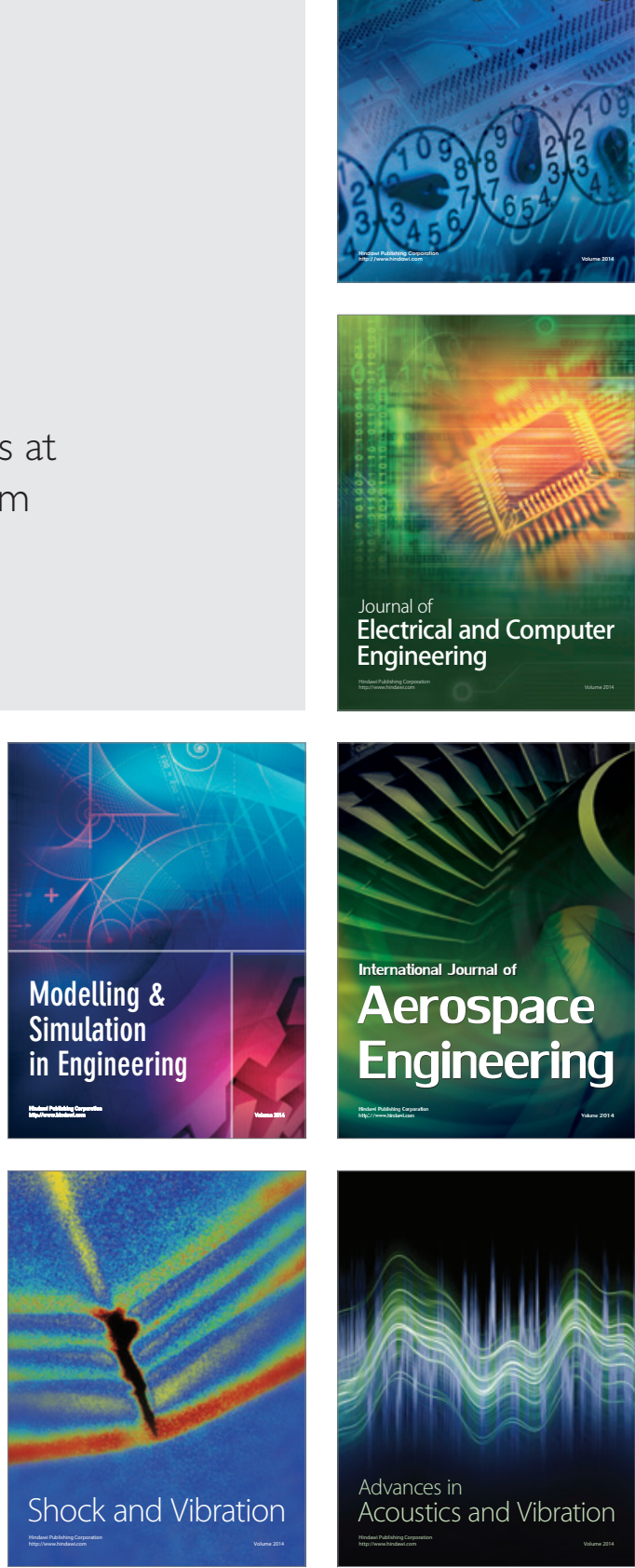